\title{
EDITORIAL
}

\section{SYNERGISM IN TECHNOLOGY ASSESSMENT}

\author{
Ted R. Tyson \\ Tyson Consulting Group, U.S.A.
}

In 1899, Charles H. Duell, Commissioner of the U.S. Office of Patents, urged President McKinley to abolish the Patent Office by saying, "Everything that can be invented has been invented." Fortunately for the health care industry, there have been more significant "medical inventions" in the 89 years following Duell's utterance than in all of recorded history preceding it.

There is now a crisis in medical technology, and it has not been caused by a lack of ideas from innovative clinicians, inventors, and scientists. Instead, it is a result of sincere, but often spasmodic, efforts to control health care costs, which in the minds of many observers threaten the national economy, if not the country's survival.

"Cost-containment" measures have given us prospective payment systems, diagnosisrelated groups, utilization review, and case-mix management, to name a few of the mechanisms being used.

The newest and fastest growing method of cost control is "managed care." Simply put, managed care is a system that strives for medical efficiency, and it rewards providers who are able to control costs by altering the delivery of medical services.

But how does this system affect new or modified medical technology? The potential impact was succinctly expressed by the National Committee for Quality Health Care:

\begin{abstract}
What is highly uncertain is how managed care systems will value technologies whose primary quality and economic benefits do not immediately accrue to the system, but are realized in the long-term or by other parties. Should managed care dampen the process of incremental advance by creating a wide zone of technological uncertainty, important opportunities could be lost because innovators fail to take the early steps. (2)
\end{abstract}

The fact is that "managed care," and all of its ultimate progeny, will force drastic changes in the way that new methods and products are conceived, evaluated, and utilized.

The old system was basically a free market, which is generally regulated by the laws of supply and demand rather than by restrictive economic sanctions. Under it, a product was developed if there were positive answers to a few key questions.

- Buyer questions. Is it useful to someone? Does it work? Is there enough money to buy it?

- Supplier questions. Can it be made? Is there minimal competition? Can it be sold at a profit? 
Perhaps this model is overly simplistic, but the development process for medical products has been reactive, informal, and unplanned, and the buying process for medical products has often been emotional, egocentric, and unprioritized.

The luxury of operating under those circumstances is forever gone, and the adoption of future technologies must be planned in a more businesslike and scientific fashion.

This reorganization will demand "synergism in technology assessment." Taber's Cyclopedic Medical Dictionary defines synergism as "the harmonious action of two agents - producing an effect which neither could produce alone or an effect which is greater than the total effects of each agent operating by itself."

In the case of technology assessment the two agents are:

1. academic and provider community, including clinicians, research scientists, and professional technology assessment organizations; and

2. medical products industry, including device and drug manufacturers, design firms, and OEM and raw materials suppliers.

Not withstanding the many exemplary accomplishments and relationships between the two groups in the past, the truth is that joint technology assessment activities have for the most part been reflexive, sporadic, unsystematized, short-term oriented, and all too frequently adversarial. If these characteristics continue to exist under an ever more rigid and cost-sensitive reimbursement system, the result will be a sharp decrease in both the number and kinds of medical products that are needed.

Therefore, this is a call for a new era of "synergism in medical technology assessment," in which the two "agents" jointly subscribe to the following precepts.

1. The academic and provider community will concentrate assessment activities on technologies that lower morbidity and mortality and improve the quality of life for the largest number of people whose needs have been certified by gap analysis. Orphan drugs and devices, and the cost of their assessment, must be supported by government and/or charity, not by providers or suppliers.

2. The medical products industry will view technology assessment as a planned and organized method of identifying, prioritizing, evaluating, and selecting medical techologies based on their ability to improve a company's image, market position, and return-on-investment, while at the same time improving the cost, delivery, and quality of health care (3).

3. Technology assessment is not idea generation, or invention, or research and development; therefore, the assessment process will be limited to technologies in which proof of principle has been validated, technical feasibility demonstrated, and economic impact and added value projected.

4. Emphasis will be placed on technologies that (a) are not minor modifications of existing, widely used, and still-functional products; (b)increase the productivity and/or lower the cost of health care labor; (c) allow consumers to practice more self-diagnosis and treatment; (d) deal with prevention and wellness; (e) direct chronic care away from all institutions and into the home; (f) accelerate the independence and self-support of the permanently disabled; and $(\mathrm{g})$ have above-average reimbursement potential.

5. High assessment priority will also be given to technologies that are conceived and/or developed (a) in economically depressed areas; (b) with the use of public funds; and (c) by individuals and small businesses. 
6. The "agents" will screen technologies by using a set of weighted criteria that attach equal importance to the broad areas of clinical efficacy, market utilization, and commercial success. The screen will quantify the validity of a technology for further and more comprehensive assessment.

Adoption of these principles will not guarantee that only the necessary and successful technologies will be used in the future. However, using them as a basis for planning will significantly improve the selection of technologies that will optimize health care for the broadest spectrum of people; address the changing needs of consumers and providers; can be financed and paid for under increasing pressure for costcontainment; and will result in products that can be made and sold at a profit.

A 1987 report from Arthur Andersen and Co. and the American College of HealthCare Executives concluded:

The size of the federal deficit and the increasing cost of care combine to create potential pressure to limit services, especially high cost technology - the healthcare sector and its consumers may need to accept some constraints on technological innovations and extraordinary medical procedures; this clearly is a form of rationing that might result from national fiscal pressures. The key, then, is how such constraints are determined and implemented - who will win and who will lose. (1)

A synergistic approach to technology assessment, that puts the needs of the consumer first, and that attaches equal weight to the requirements of the clinician and those of the manufacturer, cannot help but result in a greater number of "winners."

\section{REFERENCES}

1. Arthur Andersen \& Company and The American College of Health Care Executives. The future of health care: Changes and choices, 1987.

2. The National Committee for Quality Health Care. Medical technology in the competitive market: A health policy white paper, 1987.

3. Tyson Consulting Group. Using technology assessment to develop products that will sell. Medical Design \& Manufacturing Conference, June 1988. 